Konrad Szcześniak (D) Universidade Palacký de Olomouc Universidade de Silésia konrad.szczesniak@upol.cz

\title{
Os aspetos regulares e irregulares da construção ter PRON INF ${ }^{1}$
}

\section{Resumo:}

O presente estudo inclui uma análise cognitiva da construção gramatical ter PRON INF (exemplificada pela bem-conhecida expressão Não tem de/que agradecer). Mostra-se que a construção tem uma forte preferência por usos negativos e na maioria dos casos, serve para exprimir sentidos de 'incapacidade'. Embora possua algumas caraterísticas em comum com estruturas interrogativas indiretas, a forma da construção permanece idiossincrática como resultado da convencionalização de frasemas e de lacunas lexicais. As propriedades aqui descritas servem de ponto de partida para discussão da sua significância na aquisição e no uso da construção. Entender-se-á que a idiossincrasia, presente em todas as construções ("emparelhamentos de forma e sentido"), exige uma imersão profunda no input (apesar da opinião generativa e apesar do argumento da pobreza do estímulo). No presente trabalho, propõe-se que as propriedades previsíveis (regulares) só podem simplificar e acelerar o processo de aprendizagem e assim deve-se-lhes atribuir mais importância nos atuais modelos baseados no uso.

Palavras-chave: idiossincrasia, arbitrariedade, construção, input

${ }^{1}$ No processo de elaboração deste trabalho, beneficiei de inúmeras conversas com Maria José Alegre que me sugeriu novas questões interessantes. 


\section{Abstract: \\ Os aspetos regulares e irregulares da construção ter PRON INF}

This study offers a cognitive analysis of the grammatical construction ter PRON INF (present in the familiar expression Não tem de agradecer). The construction is shown to have a preference for negative uses, and for the most part, it serves to express 'incapacity'. Although it shares some characteristics with indirect question structures, the form of the construction is idiosyncratic as a result of conventionalization of fixed phrases and lexical gaps. These properties are then discussed in terms of their significance for acquisition and use of the construction. It will be assumed that the construction and its idiosyncrasy, otherwise widely believed to underlie all form-meaning pairings, require heavy exposure to input (contra the generative opinion or the poverty of the stimulus argument). However, the present study suggests that predictable (regular) properties cannot but simplify and expedite the learning process and should therefore receive a more prominent place in current usage-based models.

Keywords: idiosyncrasy, arbitrariness, construction, input

\section{Introdução}

Uma construção presente na língua portuguesa possui uma forma bastante extraordinária e exprime um significado que não segue diretamente dos conteúdos semânticos das palavras nela usadas.

(1) ...sem ter como nem para onde fugir... (O Corpus do Português, $\mathrm{CPE}^{2}$ )

O exemplo acima pode ser parafraseado como 'sem poder fugir'. Em tais usos, o verbo ter é seguido de um pronome interrogativo e de um infinitivo. Trata-se de um comportamento sintático pouco típico de um verbo predominantemente transitivo com funções auxiliares. Normalmente, o verbo ter não aparece junto a pronomes interrogativos em outros usos, para além da função de exprimir a possibilidade

${ }^{2}$ Todos os exemplos marcados como CPE ou CPB vêm das partes europeia e brasileira do Corpus do Português, da Universidade Brigham Young, [on-line] http://www.corpusdoportugues.org/. 
ilustrada em $(1)^{3}$. O verbo ter pode ser seguido de muitos outros pronomes interrogativos:

(2) a. Lara, não tenho o que fazer. (Leonardo Santos Medeiros, A Parte Bonita Da Vida)

b. Sonho apenas em não ter onde me pendurar. (Lucas Cordeiro, Sussurro e codeína)

c. ...para continuarem a sentir-se felizes juntos, teriam de ter por que lutar (CPE)

d. ...se sabe de alguma coisa e tem como provar denuncie, caso contrário cale-se (CPE)

e. ...nem sempre tenho quem fotografar (CPE)

Além disso, a construção ocorre com alguns pronomes preposicionais (Borregana, 1996: 159):

(3) a. Não tenho de onde tirar palavras. (CPB)

b. Não tens com que te preocupar (CPE)

c. Não tem para onde ir (CPE)

d. sem ter com quem falar ... sucumbe aos medos e receios (Eduard M.M. Costa, O Espelho, 2007)

A forma da construção pode ser descrita como em (4), onde PRON é um pronome interrogativo opcionalmente precedido de uma preposição, e seguido de INF, um infinitivo.

(4) ter PRON INF

${ }^{3}$ Embora um complemento directo possa ser introduzido através de um pronome interrogativo (Svobodová, 2014: 49), pelo que existem usos como tenho o que comprei, o verbo ter normalmente não é seguido de pronomes interrogativos em conjunto com infinitivos em outros usos senão os de expressão de possibilidade aqui discutida. 


\section{Propriedades especiais do uso e significado da construção}

A construção aqui analisada possui várias propriedades que fazem parte dos conhecimentos linguísticos empregados por qualquer falante competente do português. A questão central discutida no presente trabalho é de onde vêm tais conhecimentos? Será que as caraterísticas da construção só podem ser encontradas no input (input), ou seja, no uso da linguagem que serve de modelo para as crianças durante a aprendizagem da língua? Ou existem outras maneiras de descobrir o funcionamento da construção, sem que haja necessidade de observar todos os pormenores no uso da língua. Tal cenário é a hipótese principal do nativismo de Chomsky que argumentou que o input linguístico é demasiado fragmentário (a chamada "pobreza do estímulo", poverty of the stimulus) para explicar o bem-sucedido resultado final da aquisição do sistema complexo da língua materna (Chomsky, 2000: 56). Por outro lado, segundo a linguística cognitiva, o falante utiliza "rotinas cognitivas convencionalizadas ou estabelecidas pelo uso dentro de uma comunidade linguística" (Soares da Silva, Jakubowicz Batoréo, 2010: 231), pelo que o input tem um papel principal na aprendizagem e o que o falante sabe é um reflexo do que se pode encontrar no uso geral (Bybee, 2010: 116). A seguir são tratadas algumas caraterísticas especiais da construção ter PRON INF; que depois vão servir de ponto de partida para a discussão do papel do input na aquisição da língua.

\subsection{Significados negativos}

Uma propriedade importante da construção é a forte preponderância de usos negativos à custa dos afirmativos. Uma busca pelo Corpus do Português Europeu mostra que a maioria dos usos da construção tem a forma sintática negativa. Por exemplo, o verbo pagar aparece na construção 64 vezes e, em todos os casos, o verbo tem a forma negativa (mais frequentes são os usos na forma da primeira e terceira pessoa: 18 vezes com tenho e 20 com tem).
a. ...não tenho como pagar essa quantia (CPE)
b. ... não tem como pagar as prestações ... (CPE)
c. As rendas aumentam e muitos receiam não ter como pagar (CPE) 
d. Eu não o fiz por que não teria como pagar (CPE)

Além da partícula não, a negação é evidente através de outros meios tais como "expressões autonegativas" (Móia, 2016: 328), ou a preposição sem.

e. ...ninguém terá como pagar as compras (oinsurgente.org $-21.04 .2017)$

f. ... nunca temos como definir-nos criticamente (Oswaldo Porchat Pereira, Rumo ao ceticismo, 2007)

g. ...sem ter como pagar contas (CPE)

Embora a construção possa ser usada sem marcadores de negação, a interpretação pressupõe normalmente uma negação no plano de fundo. Por exemplo, uma pergunta como O senhor tem como pagar as despesas? leva em conta um provável cenário negativo em que o ouvinte pode bem não ter como pagar.

\subsection{Diferenças com a construção ter PRON-INDEF a INF}

A construção ter pron inf difere duma construção cuja forma se assemelha à discutida aqui e que também envolve o uso de um pronome. Nomeadamente, na construção ilustrada em (6) o verbo ter leva os pronomes nada ou algo e a oração pseudo-relativa para fazer (Svobodová, 2014: 98):

(6) a. Os alunos não tinham nada para fazer (cf. Os alunos não tinham o que fazer)

b. É bom ter algo para fazer (cf. É bom ter o que fazer)

À primeira vista, o significado transmitido por esta construção parece corresponder ao observado em frases baseadas na construção ter pron inf. Não ter nada para fazer é para todos os efeitos o mesmo que não ter o que fazer. No entanto, exemplos com outros verbos em alguns contextos mostram que a sinonímia tem os seus limites.

(7) ter PRON-INDEF a INF

a. $\mathrm{O}$ candidato não teve nada a dizer sobre o assunto

b. Uma testemunha ocular afirma ter algo a dizer sobre o acidente 
(8) ter PRON INF

a. $\mathrm{O}$ candidato não teve o que dizer sobre o assunto

b. Tenho o que dizer sobre o acidente

\subsection{Estrutura relativa ou interrogativa}

A presente construção não é um caso especial de construção relativa. Apesar de o pronome relativo poder aparecer após um potencial substantivo elíptico, como no seguinte exemplo (9), tal inserção não é possível em todos os usos (10).

(9) a. Não tenho (lugar) onde ficar.

b. Não temos (razões) porque rejeitar a ideia.

(10) a. *Não tenho pessoas quem perguntar.

b. ${ }^{*} \mathrm{O}$ candidato diz não ter segredos o que esconder.

Além disso, a construção permite opções não disponíveis em orações relativas. Por exemplo, o pronome interrogativo pode ser seguido de uma locução preposicional:

(11) a. Não tenho onde em casa guardar tantas malas. (cf. *Não tenho lugar onde em casa guardar tantas malas.)

b. Não tenho para quem da família dar as roupas de bebé.

Por outro lado, a forma da oração pronominal possível na presente construção parece ser a mesma que a disponível nas frases interrogativas indiretas (12a-14a).

(12) a. Deve-se começar perguntando por onde começar. (Luiz Gonzaga Teixeira, Utopia e Marx)

b. ...delinear um plano, somente para ter por onde começar. (Catarina Araújo, Além Tejo).

(13) a. ...numa encruzilhada e não sabes para onde ir. (Fiama Hasse Pais Brandão, Em cada pedra)

b. Porque não temos para onde ir. (José Vegar, Passaporte para o Céu) 
(14) a. ......eu nem sei em que pensar. (Cristina Dias Allessandrini, Vida de Uma Grande Garota)

b. ...sem ter em que pensar, a mente voltava a seus problemas. (Cristina Pereyra, Os Segredos do Rio)

\subsection{Lacunas}

Embora a construção seja usada com uma variedade de pronomesapresentados acima nos exemplos (2) e (3)-ela não emprega, de forma conspícua, o pronome quando. É o caso tanto do português europeu como do português do Brasil: os falantes das duas variedades não só acham incorretas frases como (15), mas também não entendem o que elas poderiam significar, ou seja, as pessoas não veem analogia entre frases com quando e as com os restantes pronomes atestados na construção.

(15) *Não tenho quando escrever (= 'não tenho tempo para escrever') Também ausentes na construção são os pronomes quanto e qual.

\subsection{Formas convencionalizadas}

Alguns usos da construção estão sujeitos a pressões de convencionalização. Embora sejam teoricamente gramaticais, cedem lugar a outras expressões mais idiomáticas: Para exprimir o sentido de 'forte desespero capaz de levar uma pessoa a comportamentos precipitados' usa-se normalmente o fraseologismo não ter nada a perder, e embora o mesmo sentido possa ser transmitido através da construção ter PRON INF, como no exemplo (16), tais usos não são frequentes. Apesar de poder ser considerado perfeitamente sinónimo de não ter nada a perder, o seguinte exemplo parece ter algo de antiquado e pouco natural no uso coloquial do português.

(16) Não tenho o que perder.

De forma semelhante, a construção exibe preferências (por pronomes específicos) que parecem ser ditadas por verbos. Por exemplo, no português moderno, para exprimir 'dificuldade de pagar', a construção serve-se do pronome como: 
(17) Em dois anos, reduziu-se o número de portugueses que diz não ter como pagar uma semana de férias por ano fora de casa. (CPE) Porém, até ao século 19, a forma preferida em que a construção era empregada em tais contextos incluía a combinação com que:

(18) ...não ter com que pagar aos criados que o serviam (Luís Cacegas, Vida de dom frei Bartolomeu, 1619)

(19) Falir de bens, fazer bancarrota não ter com que pagar aos credores (Esboço de hum diccionario juridico, 1827)

Por último, no que diz respeito à convencionalização, convém acrescentar que existem expressões fixas baseadas na construção como o frasema não ter onde cair morto cujo sentido de 'ser pobre, estar sem dinheiro' (Nascentes e Nascentes, 1987: 46) surge como consequência da convencionalização, não sendo possível inferi-lo a partir das palavras cair ou morto. Para saber usar tais frasemas, é preciso seguir o exemplo observado no uso num contexto informativo. De forma semelhante, também expressões fixas mais transparentes como não tem de quê (agradecer) exigem que os falantes sigam um padrão estabelecido pelo uso convencional. Mesmo que o aprendente consiga adivinhar o sentido e a função da fórmula não tem de que agradecer, isto não garante competência, visto que, sem testemunhar o uso, não tem como saber que é essa a resposta natural e adequada a agradecimentos. Sem o benefício do input como modelo, é pouco provável que o aprendente seja capaz de acertar em tais frasemas sozinho.

\section{O lado irregular e o regular da linguagem}

A construção ter PRON INF é um exemplo de estrutura idiossincrática. A sua forma, função e uso escondem irregularidades que não podem ser adquiridas de outra maneira a não ser observar o input e seguir (repetir) o que nele se ouve (ou vê). As imprevisíveis caraterísticas idiomáticas da construção acima enumeradas mostram que a sua aquisição deve depender do input a um grau mais alto do que sugeria Chomsky. Recorde-se que Chomsky (1988: 151) reduzia o papel do input a um mero "gatilho" (trigger) que punha em marcha o processo 
de aquisição, mas não era necessário em grandes quantidades no desenvolvimento linguístico da criança. Tal visão tem sido questionada nas últimas três décadas por linguistas cognitivos. Estudos conduzidos (especialmente no campo da Gramática de Construções) mostraram que a quantidade da idiossincrasia presente em cada língua é mais elevada do que supunha a Gramática Generativa de Chomsky. Segundo Taylor (2012: 72) “o elemento idiomático entranha-se em cada recanto da língua ... praticamente tudo numa língua é idiomático em maior ou menor grau ... o que é excecional é o inteiramente regular e composicional." Assim, o lado irregular e imprevisível da linguagem tornou-se a marca distintiva das novas abordagens a construções gramaticais. Goldberg define-as como "emparelhamentos de forma e sentido" (form-meaning pairings, Goldberg, 2006: 123) caraterizados por um grau de imprevisibilidade e idiossincrasia. É o que se verifica no caso da construção ter PRON INF: Ela não segue as regras gerais mais básicas da gramática de núcleo (core grammar). Não há regras gerativas diretamente responsáveis pelo arranjo do verbo ter com pronomes interrogativos como seus complementos. É preciso acesso ao input para saber que a construção não admite o pronome quando (Secção 2.4) ou que ela pode ser usada na forma reduzida não tem de quê (sem o verbo agradecer) como resposta a agradecimentos (Secção 2.5).

No entanto, nem tudo no comportamento da construção é imprevisível. Por exemplo, a forma da oração pronominal é a mesma que ocorre em interrogativas indiretas (2.3). Também, em todas as instâncias, o verbo depois do pronome aparece sempre no infinitivo. Para aprender não é preciso memorizar a forma de cada variante da construção (com diferentes pronomes ou diferentes verbos) inteiramente do zero. É suficiente verificar que o padrão em novos usos é o mesmo que o observado em outras realizações já conhecidas. Sendo assim, a forma do infinitivo na construção pode ser algo cuja aquisição não

4 "the idiomatic reaches into every nook and cranny of a language ... everything in a language is idiomatic to a greater or lesser degree ... it is the fully regular, the fully compositional, that is exceptional." 
exige atenção minuciosa ao input. A regularidade do infinitivo é evidente pelo facto de a construção existir em várias línguas onde, em cada caso, o segundo verbo aparece como infinitivo:

(20) Nemám kde a jak čerpat sílu.

(Checo)

Não-tenho onde e como reunir força

(Não tenho onde nem como reunir forças)

(www.babyonline.cz - 21.04.2017)

Rekla je da ima gdje spavati i nije gladna.

(Croata)

Dito é que tem onde dormir e não-está fome-ADJ

(Disse que tem onde dormir e não tem fome)

(www.jutarnji.hr - 21.04.2017)

Nie mam gdzie się podziać.

(Polaco)

Não tenho onde se hospedar

(Não tenho onde me hospedar)

(Katarzyna Miszczuk, Ja, potępiona, 2012)

...немає де спати.

(Ucraniano)

Não-tem onde dormir

(Não tem onde dormir)

(I. Штогрін, Історія мужності, 2015)

No tengo donde vivir.

(Espanhol)

(Não tenho onde viver)

(José M. Moral, Incondicionalmente Amados, 2011)

Non posso, non posso, non ho come pagare.

(Italiano)

(Não posso, não posso, não tenho como pagar)

(Gherardo De Rossi, Commedie di Gio, 1792) 


\section{Conclusões}

O núcleo (core) da gramática estudado por generativistas continha só regularidades: formas governadas por algumas regras gerais. A regularidade era considerada a marca principal da linguagem no modelo generativo, em que as irregularidades eram relegadas para a periferia, tratadas como exceções para memorizar. Mas como observaram Culicover \& Jackendoff (2005: 26), a periferia representa a maior parte da linguagem e "levanta um problema pelo menos tão grande para a aquisição como o núcleo". Assim, na linguística cognitiva o quadro é inverso: o sistema linguístico é, no seu cerne, irregular e idiossincrático, sendo o lado regular encarado como algo atípico e praticamente irrelevante, porque tudo tem de ser memorizado, quer seja irregular e excecional, quer seja regular. Segundo Goldberg (2006: 5) todas as construções são aprendidas e armazenadas, mesmo as perfeitamente previsíveis, desde que ocorram com bastante frequência. Por outras palavras, o que é relegado para a periferia nos modelos cognitivos são as caraterísticas previsíveis e regulares. Tal marginalização do lado regular da linguagem é provavelmente um erro tão sério e uma atitude tão extrema como a decisão de Chomsky de desconsiderar as estruturas idiossincráticas. Um modelo de gramática adequado deveria dar importância tanto à idiossincrasia inerente à linguagem como à regularidade como componentes essenciais na aquisição e uso. Negar importância ao que é regular e partir do princípio que o falante memoriza tudo na língua seria como dizer que essa língua não tem regras, mas só exceções.

\section{Referências bibliográficas}

BORREgANA, A. A. (1996), Gramática Universal. Língua Portuguesa, Texto Editora, Lisboa.

BYBEE, J. (2010), Language, Usage and Cognition, Cambridge University

Press, Cambridge, https://doi.org/10.1017/CBO9780511750526.

CHOMSKY, N. (1988), Language and Problems of Knowledge, MIT Press, Cambridge, MA. 
CHOMSKY, N. (2000), New Horizons in the Study of Language and Mind, Cambridge University Press, Cambridge, https://doi.org/10.1017/ CBO9780511811937.

CULICOVER, P., JACKENDOFF, R. (2005), Simpler Syntax, Oxford University Press, Oxford, https://doi.org/10.1093/acprof:oso/9780199271 092.001.0001.

GOLDBERG, A. (1995), Constructions: A Construction Grammar Approach to Argument, The University of Chicago Press, Chicago.

GOLDBERG, A. (2006), Constructions at Work: The Nature of Generalization in Language, Oxford University Press, Oxford.

DAVIES, M. (2015), O Corpus do Português. Criado por Mark Davies. Disponibilizado pela Universidade Brigham Young (2015), [on-line] http:// www.corpusdoportugues.org/ - 26.09.2019.

MÓIA, T. (2016), "Semântica e Pragmática” em: Martins, A.M., Carrilho, E. (eds.), Manual de Linguística Portuguesa, Mouton De Gruyter, Berlin, pp. 308-335, https://doi.org/10.1515/9783110368840-014.

NASCENTES, A., NASCENTES, O. A. (1987), Tesouro da fraseologia brasileira, Nova Frontera, Rio de Janeiro.

SVOBODOVÁ, I. (2014), Sintaxe da Língua Portuguesa, Masarykova univerzita, Brno.

SOARES DA SILVA, A., JAKUBOWICZ BATORÉO, H. (2010), “Gramática Cognitiva: estruturação conceptual, arquitectura e aplicações” em Brito, A.M. (ed.), Gramática: História, Teorias, Aplicações, Universidade do Porto, Porto, pp. 229-252.

TAYLOR, J. (2012), The Mental Corpus. How Language is Represented in the Mind, Oxford University Press, Oxford, https://doi.org/10.1093/acpr of:oso/9780199290802.001.0001. 